\title{
Effect of mitral valve replacement on left ventricular function in mitral regurgitation
}

\author{
HEIKKI V HUIKURI \\ From the Division of Cardiology, Department of Medicine, University of Oulu, University Central Hospital, Oulu, \\ Finland
}

SUMMARY To evaluate the effect of mitral valve replacement on left ventricular function in mitral regurgitation, we measured (1) the end-systolic stress/volume ratio, which is practically independent of changes in loading conditions, and (2) the left ventricular contractile reserves upon isometric exercise, both before and one year after mitral valve replacement in 11 patients with mitral regurgitation.

The end-systolic stress/volume ratio increased, though the ejection fraction decreased after mitral valve replacement. The ejection fraction decreased and the end-systolic stress/volume ratio remained unchanged during isometric exercise before operation, whereas afterwards the ejection fraction remained unchanged and the end-systolic stress/volume ratio increased during exercise.

Ventricular function improves after mitral valve replacement in patients with mitral regurgitation, though the ejection fraction, which is affected by altered loading conditions, deteriorates. The left ventricular response to stress caused by isometric exercise is also improved after surgery.

A major problem in assessing the effects of valve replacement on ventricular function is the difficulty experienced in separating the effects of removal of abnormal loading conditions from those of a primary change in myocardial function. In aortic valve diseases, valve replacement results in an improvement in the indices of ventricular function. ${ }^{12}$ In mitral regurgitation, however, the ejection phase contractile measures often deteriorate after operation, ${ }^{34}$ and the reason is thought to be the increased afterload caused by a competent mitral valve. ${ }^{3-5}$

The purpose of the present study was to evaluate left ventricular function before and after mitral valve replacement in patients with chronic mitral regurgitation by using the end-systolic wall stress/end-systolic volume ratio as a measure of ventricular function. This ratio has previously been shown to be practically independent of loading conditions. Secondly, we aimed to study the influence of valve replacement on the left ventricular response to stress by using isometric exercise as a stress test.

This study was supported partly by a grant from the Finnish Foundation for Cardiovascular Research.

Accepted for publication 10 December 1982

\section{Patients and methods}

Eleven consecutive patients with moderate or severe mitral regurgitation $(3+/ 4+$ or $4+/ 4+$ mitral regurgitation in cineangiography), and who underwent mitral valve replacement, participated in the study. The patients were studied by cardiac catheterisation before $?$ operation and 12 months after mitral valve replace- $\frac{5}{3}$ ment. The patients who also had aortic valve disease (more than $10 \mathrm{mmHg}$ systolic gradient across the aor- $O$ tic valve and/or clinical signs of aortic regurgitation) were excluded, as were those with significant mitral 음 stenosis (mitral valve area under $2.0 \mathrm{~cm}^{2}$ ). Three $>$ patients were excluded from the consecutive series because of poor pre- or postoperative angiographic N visualisation of the left ventricle.

The clinical data concerning the patients, five men and six women are presented in Table 1 . Their mean $\omega$ age was $51 \pm 5$ years. Six patients had atrial fibrillation both before and after operation and five were inco sinus rhythm. The chronic mitral regurgitation was considered to be the result of rheumatic fever in five $\stackrel{+}{+}$ patients, three had ruptured chordae tendineae, and $\frac{T}{0}$ three were considered to have "floppy mitral valve". All the patients were receiving digitalis and diuretics $?$ both before and after operation. None was receiving $\mathbb{2}$ beta blockers or vasodilating agents. Nine patients 
Table 1 Clinical data

\begin{tabular}{|c|c|c|c|c|c|}
\hline \multirow[t]{2}{*}{ Case No } & \multirow[t]{2}{*}{ Age/sex } & \multicolumn{2}{|l|}{ NYHA } & \multirow[t]{2}{*}{ Duration of symptoms (mth) } & \multirow[t]{2}{*}{ Type of prostheses } \\
\hline & & Preop & Postop & & \\
\hline $\begin{array}{l}1 \\
2 \\
3 \\
4 \\
5 \\
6 \\
7 \\
8 \\
9 \\
10 \\
11 \\
\text { Mean } \pm S D\end{array}$ & $\begin{array}{ll}54 & M \\
40 & F \\
51 & M \\
48 & M \\
56 & F \\
52 & F \\
50 & F \\
54 & M \\
56 & F \\
43 & F \\
54 & M \\
51 \pm 5\end{array}$ & $\begin{array}{l}3 \\
3 \\
4 \\
3 \\
3 \\
3 \\
3 \\
3 \\
4 \\
3 \\
3 \\
3 \cdot 2 \pm 0.5\end{array}$ & $\begin{array}{l}2 \\
1 \\
2 \\
1 \\
2 \\
2 \\
1 \\
2 \\
2 \\
2 \\
2 \\
1 \cdot 7 \pm 0.4\end{array}$ & $\begin{array}{c}60 \\
30 \\
60 \\
10 \\
12 \\
20 \\
84 \\
12 \\
120 \\
6 \\
60 \\
43 \pm 37\end{array}$ & $\begin{array}{l}\text { St. Jude } \\
\text { Björk-Shiley } \\
\text { Björk-Shiley } \\
\text { Björk-Shiley } \\
\text { Björk-Shiley } \\
\text { Björk-Shiley } \\
\text { Björk-Shiley } \\
\text { St. Jude } \\
\text { Björk-Shiley } \\
\text { Björk-Shiley } \\
\text { Björk-Shiley }\end{array}$ \\
\hline
\end{tabular}

NYHA, New York Heart Association's classification of grade of symptoms.

had a Björk-Shiley valve prosthesis and two had a St Jude medical valve prosthesis. All patients gave their informed consent to the preoperative and postoperative catheterisations and the isometric handgrip exercise tests.

\section{PREOPERATIVE AND POSTOPERATIVE STUDIES}

Preoperative and postoperative right and left heart catheterisation was performed via the cubital vein and the brachial artery. Right atrial pressures, pulmonary pressures, and pulmonary capillary wedge pressures were recorded with a Statham P23Ia transducer. Left ventricular pressures were recorded with a high fidelity Millar tip transducer. A data acquisition system (Hewlett-Packard 5600B) was used for the standard recording of pressures. Selective biplane left ventricular cineangiography was performed in the $45^{\circ}$ right anterior oblique position. The filming of the left ventricle was performed at biplane in the $45^{\circ}$ right anterior oblique and $45^{\circ}$ left anterior oblique projections. No coronary angiography or coronary bypass surgery was performed.

\section{ISOMETRIC EXERCISE TESTS}

The left ventricular pressures were recorded after preoperative and postoperative angiography until they returned to baseline levels. Then at least 20 minutes after resting cineangiography, the patients were asked to perform a handgrip test. Each patient's maximal voluntary handgrip contraction was determined as the average of two or three maximal attempts using a hand dynamometer (Martin, Germany) held in the left hand. After calculation of the maximal voluntary handgrip contraction, the patients were asked to perform a sustained handgrip at $30 \%$ of the mean maximal voluntary handgrip contraction. The patients were watched carefully to ensure they avoided the Valsalva manoeuvre. Left ventricular pressures and heart rate were determined every minute for four minutes during the sustained grip. Left ventricular cineangiography was then performed again, with the patient still maintaining the grip.

\section{MEASUREMENTS}

Left ventricular volumes were measured from one or two representative beats; postextrasystolic beats were discarded. In the patients with atrial fibrillation the volume measurements were taken on those beats that most closely approximated the average $R R$ interval for the basal ventricular response. In the postoperative angiograms a cycle length was chosen for analysis which most closely resembled that of the preoperative cycle. The greatest individual variation in $R R$ cycle lengths in the preoperative and the postoperative measurements was $0.14 \mathrm{~s}$. The contours of the left ventricle were digitised at biplane on the projection screen with a sonic pen using the HP 5600B and the area-length method for volumes. ${ }^{6}$ The measured volumes were changed to actual volumes by using the regression equations previously established in our laboratory. ${ }^{7}$ The left ventricular pressure curve was recorded simultaneously with the angiogram at a paper speed of $150 \mathrm{~mm} / \mathrm{s}$ and was digitised and synchronised with the corresponding volume data with the aid of the HP 5600B. The mitral valve area was calculated from the modified Gorlin formula as described by Hammermeister $e t a l .,{ }^{8}$ and the left ventricular mass as described by Rackley et al. 9 The mitral regurgitant fraction was measured by subtracting the stroke volume, determined by the Fick method, from the total left ventricular stroke volume. The circumferential wall stress was estimated from the formula ${ }^{10}$ : wall stress $=\left(P R_{i} / H\right)\left(a_{h}\right)\left[1-1 / 2\left(R_{i} /\right.\right.$ $B)^{2}$, where $\mathrm{P}=$ left ventricular pressure, $\mathrm{H}=$ wall thickness, $R_{i}=$ minor semiaxis, $B=$ major semiaxis, $a_{h}=\left(r_{m} / r_{m}+H / 2\right), r_{m}=B^{2} / R_{i}$. The end-systolic wall stress was estimated by measuring the pressure, wall thickness, and the minor and major semiaxes at the point of lowest end-systolic volume. The end-systolic wall stress/end-systolic volume index ratio was 
estimated by dividing the wall stress at end-systole by corresponding end-systolic volume index.

\section{STATISTICS}

The paired $t$ test was used for comparing the resting data with those obtained during isometric exercise and also the preoperative with the postoperative data.

\section{Results}

\section{CLINICAL DATA}

The clinical data are presented in Table 1. Two patients were in functional class four and the others in class three before operation. All patients had dyspnoea on exertion, but none complained of chest pain. The mean duration of the symptoms had been $43 \pm 37$ months. The mean mitral regurgitant fraction was $0 \cdot 47 \pm 14$. All the patients showed a functional improvement after mitral valve replacement, eight rising to functional class two and three to class one.

\section{PREOPERATIVE AND POSTOPERATIVE}

HAEMODYNAMIC AND ANGIOGRAPHIC DATA

The preoperative and postoperative resting haemodynamic and angiographic data are presented in Table 2 . The mean pulmonary artery pressure and the mean pulmonary capillary wedge pressure decreased significantly after mitral valve replacement. The end-systolic volume index remained unchanged, but the end-diastolic volume index decreased significantly. The ejection fraction decreased, but the end-systolic wall stress/volume ratio increased significantly after surgery (Fig. 1). The end-systolic wall stress increased significantly, and the left ven- $\frac{\mathscr{N}}{7}$ tricular mass index decreased, but not significantly.

PREOPERATIVE AND POSTOPERATIVE

HAEMODYNAMIC AND ANGIOGRAPHIC DATA AT

REST AND DURING ISOMETRIC EXERCISE

The preoperative and postoperative haemodynamic data at rest and during exercise are presented in Table $\varrho$ 3. The heart rate and left ventricular end-systolic is pressure increased significantly during exercise both $\vec{\circ}$ before and after operation, but the end-diastolic pressure remained unchanged. Table 4 presents the indi- $\vec{\omega}$ vidual values for the left ventricular volumes at rest $\frac{\rho}{\overrightarrow{ }}$ and during exercise before and after operation. The? end-systolic volume index increased during exercise $\overrightarrow{0}$ before operation, but remained unchanged after valve replacement. The end-diastolic volume index

Table 2 Pre-and postoperative resting haemodynamic and angiographic data

\begin{tabular}{|c|c|c|c|}
\hline & Preoperative & Postoperative & $p$ values \\
\hline $\begin{array}{l}\mathrm{PA}_{\text {mean }}(\mathrm{mmHg}) \\
\text { PCW }(\mathrm{mean}(\mathrm{mm}) \\
\text { ESVI }\left(\mathrm{ml} / \mathrm{m}^{2}\right) \\
\text { EDVI }\left(\mathrm{ml} / \mathrm{m}^{2}\right) \\
\text { EF }(\%) \\
\text { ESWS/ESVI } \\
\text { ESWS }\left(\mathbf{g} / \mathrm{m}^{2}\right) \\
\mathrm{LVMI}\left(\mathbf{g} / \mathrm{m}^{2}\right)\end{array}$ & $\begin{array}{l}35 \pm 15 \\
24 \pm 7 \\
56 \pm 22 \\
138 \pm 49 \\
58 \pm 8 \\
3 \cdot 3 \pm 1 \cdot 8 \\
195 \pm 46 \\
137 \pm 48\end{array}$ & $\begin{array}{l}22 \pm 6 \\
13 \pm 3 \\
51 \pm 20 \\
100 \pm 28 \\
50 \pm 10 \\
5 \cdot 4 \pm 2 \cdot 4 \\
252 \pm 50 \\
115 \pm 30\end{array}$ & $\begin{array}{l}<0.001 \\
<0.001 \\
\text { NS } \\
<0.02 \\
<0.025 \\
<0.02 \\
<0.05 \\
\text { NS }\end{array}$ \\
\hline
\end{tabular}

Mean values $\pm S D$; $p$ values with paired $t$ test. Abbreviations: PA, pulmonary artery pressure; PCW, pulmonary capillary wedge pressure; LVMI, left ventricular mass index; for others see Tables 3 and 4.
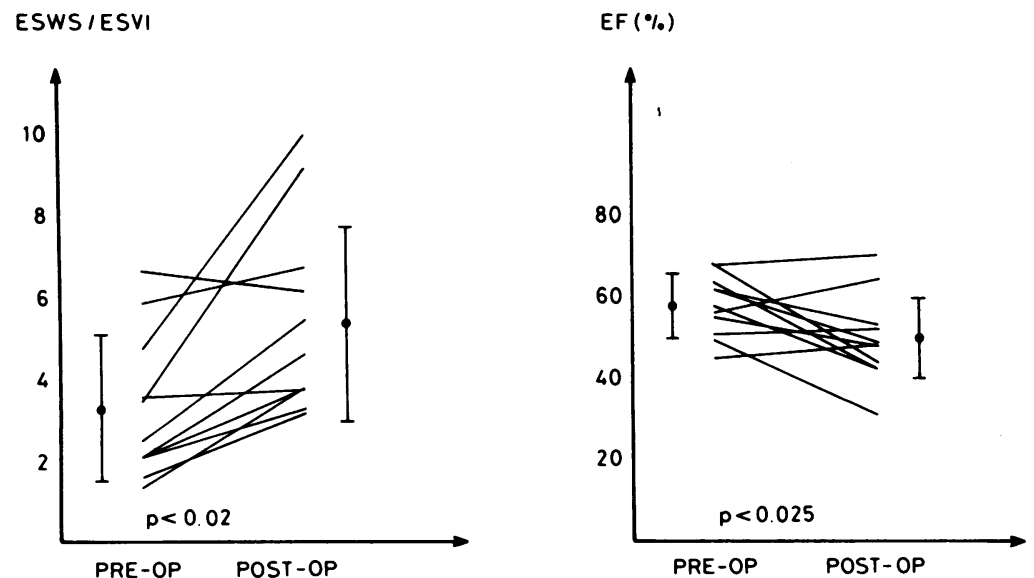

Fig. 1 Effect of mitral valve replacement on indices of ventricular function. Left panel presents the significant increase in the end-systolic stress/end-systolic volume ratio after mitral valve replacement. Right panel presents the significant decrease of the ejection fraction after mitral valve replacement. 
Table 3 Pre-and postoperative haemodynamic data at rest and during isometric exercise

\begin{tabular}{|c|c|c|c|c|c|c|c|c|c|c|c|c|}
\hline \multirow{3}{*}{$\begin{array}{l}\text { Case } \\
\text { No }\end{array}$} & \multicolumn{4}{|c|}{$H R$ (beat/min) } & \multicolumn{4}{|c|}{ LVESP $(\mathrm{mm} H g)$} & \multicolumn{4}{|c|}{$L V E D P(m m H g)$} \\
\hline & \multicolumn{2}{|l|}{ Preop } & \multicolumn{2}{|c|}{ Postop } & \multicolumn{2}{|l|}{ Preop } & \multicolumn{2}{|l|}{ Postop } & \multicolumn{2}{|l|}{ Preop } & \multicolumn{2}{|c|}{ Postop } \\
\hline & Rest & Exercise & Rest & Exercise & Rest & Exercise & Rest & Exercise & Rest & Exercise & Rest & Exercise \\
\hline $\begin{array}{l}1 \\
2 \\
3 \\
4 \\
5 \\
6 \\
7 \\
8 \\
9 \\
10 \\
11 \\
\text { Mean } \pm \text { SD } \\
\text { p value }\end{array}$ & $\begin{array}{l}68 \\
85 \\
80 \\
69 \\
85 \\
82 \\
52 \\
70 \\
77 \\
74 \\
80 \\
75 \pm 10 \\
<0 .\end{array}$ & $\begin{array}{l}113 \\
100 \\
86 \\
80 \\
95 \\
92 \\
65 \\
72 \\
80 \\
78 \\
91 \\
87 \pm 14 \\
01\end{array}$ & $\begin{array}{l}61 \\
80 \\
75 \\
68 \\
80 \\
65 \\
65 \\
72 \\
60 \\
63 \\
58 \\
68 \pm 8 \\
<0\end{array}$ & $\begin{array}{l}68 \\
94 \\
82 \\
75 \\
88 \\
71 \\
71 \\
90 \\
71 \\
78 \\
73 \\
78 \pm 9\end{array}$ & $\begin{array}{l}122 \\
111 \\
138 \\
144 \\
121 \\
113 \\
108 \\
161 \\
122 \\
109 \\
135 \\
126 \pm 17 \\
<0\end{array}$ & $\begin{array}{l}124 \\
133 \\
143 \\
162 \\
151 \\
126 \\
125 \\
165 \\
128 \\
138 \\
155 \\
141 \neq 15 \\
001\end{array}$ & $\begin{array}{l}137 \\
126 \\
140 \\
140 \\
132 \\
116 \\
104 \\
133 \\
125 \\
106 \\
134 \\
127 \pm 13 \\
<0\end{array}$ & $\begin{array}{l}145 \\
145 \\
152 \\
147 \\
145 \\
140 \\
110 \\
147 \\
133 \\
109 \\
151 \\
139 \pm 15 \\
001\end{array}$ & $\begin{array}{l}19 \\
17 \\
14 \\
13 \\
36 \\
26 \\
13 \\
13 \\
20 \\
12 \\
20 \\
18 \pm 7\end{array}$ & $\begin{array}{l}18 \\
20 \\
15 \\
11 \\
34 \\
26 \\
15 \\
13 \\
21 \\
10 \\
15 \\
18 \pm 7\end{array}$ & $\begin{array}{c}15 \\
12 \\
12 \\
15 \\
19 \\
9 \\
12 \\
10 \\
14 \\
8 \\
15 \\
13 \pm 3\end{array}$ & $\begin{array}{l}15 \\
14 \\
12 \\
11 \\
22 \\
13 \\
11 \\
11 \\
19 \\
11 \\
18 \\
14 \pm 4\end{array}$ \\
\hline
\end{tabular}

p values with paired t test. Abbreviations: HR, heart rate; LVESP, left ventricular end-systolic pressure; LVEDP, left ventricular end-diastolic pressure; preop, preoperative; postop, postoperative.

Table 4 Pre-and postoperative left ventricular volumes at rest and during isometric exercise

\begin{tabular}{|c|c|c|c|c|c|c|c|c|}
\hline \multirow[t]{3}{*}{ Case No } & \multicolumn{4}{|c|}{$E S V I\left(\mathrm{ml} / \mathrm{m}^{2}\right)$} & \multicolumn{4}{|c|}{$E D V I\left(\mathrm{ml} / \mathrm{m}^{2}\right)$} \\
\hline & \multicolumn{2}{|l|}{ Preop } & \multicolumn{2}{|l|}{ Postop } & \multicolumn{2}{|l|}{ Preop } & \multicolumn{2}{|l|}{ Postop } \\
\hline & Rest & Exercise & Rest & Exercise & Rest & Exercise & Rest & Exercise \\
\hline $\begin{array}{l}1 \\
2 \\
3 \\
4 \\
5 \\
6 \\
7 \\
8 \\
9 \\
10 \\
11 \\
\text { Mean } \pm S D \\
\text { p value }\end{array}$ & $\begin{array}{l}77 \\
77 \\
24 \\
47 \\
60 \\
52 \\
42 \\
25 \\
57 \\
61 \\
94 \\
56 \pm 22\end{array}$ & $\begin{array}{l}81 \\
74 \\
34 \\
52 \\
61 \\
54 \\
45 \\
28 \\
80 \\
68 \\
96 \\
61 \pm 21\end{array}$ & $\begin{array}{l}88 \\
53 \\
45 \\
49 \\
65 \\
20 \\
26 \\
37 \\
53 \\
52 \\
77 \\
51 \pm 20\end{array}$ & $\begin{array}{l}90 \\
53 \\
44 \\
45 \\
74 \\
19 \\
30 \\
38 \\
59 \\
42 \\
83 \\
52 \pm 22\end{array}$ & $\begin{array}{l}153 \\
156 \\
68 \\
103 \\
143 \\
162 \\
95 \\
79 \\
151 \\
238 \\
170 \\
138 \pm 49\end{array}$ & $\begin{array}{l}140 \\
156 \\
68 \\
103 \\
143 \\
162 \\
95 \\
68 \\
162 \\
198 \\
151 \\
131 \pm 42\end{array}$ & $\begin{array}{c}128 \\
110 \\
79 \\
94 \\
135 \\
68 \\
73 \\
65 \\
103 \\
99 \\
148 \\
100 \pm 28\end{array}$ & $\begin{array}{r}128 \\
107 \\
81 \\
88 \\
146 \\
70 \\
74 \\
71 \\
101 \\
99 \\
142 \\
101 \pm 28\end{array}$ \\
\hline
\end{tabular}

$\mathrm{p}$ values with paired $\mathrm{t}$ test. Abbreviations: ESVI, end-systolic volume index; EDVI, end-diastolic volume index.

Table 5 Pre-and postoperative measures of left ventricular function at rest and during isometric exercise

\begin{tabular}{|c|c|c|c|c|c|c|c|c|}
\hline \multirow[t]{3}{*}{ Case No } & \multicolumn{4}{|c|}{$E F(\%)$} & \multicolumn{4}{|c|}{ ESWS/ESVI } \\
\hline & \multicolumn{2}{|l|}{ Preop } & \multicolumn{2}{|l|}{ Postop } & \multicolumn{2}{|l|}{ Preop } & \multicolumn{2}{|l|}{ Postop } \\
\hline & Rest & Exercise & Rest & Exercise & Rest & Exercise & Rest & Exercise \\
\hline $\begin{array}{l}1 \\
2 \\
3 \\
4 \\
5 \\
6 \\
7 \\
8 \\
9 \\
10 \\
11 \\
\text { Mean } \pm S D \\
\text { p value }\end{array}$ & $\begin{array}{l}50 \\
51 \\
64 \\
55 \\
58 \\
68 \\
56 \\
69 \\
62 \\
62 \\
45 \\
58 \pm 8\end{array}$ & $\begin{array}{l}43 \\
51 \\
56 \\
48 \\
57 \\
65 \\
53 \\
58 \\
51 \\
51 \\
36 \\
52 \pm 8\end{array}$ & $\begin{array}{l}31 \\
52 \\
43 \\
48 \\
52 \\
70 \\
64 \\
44 \\
49 \\
53 \\
48 \\
50 \pm 10\end{array}$ & $\begin{array}{l}30 \\
50 \\
45 \\
49 \\
49 \\
72 \\
60 \\
46 \\
41 \\
58 \\
41 \\
49 \pm 11\end{array}$ & $\begin{array}{l}2.1 \\
1.3 \\
6.7 \\
3.6 \\
2.5 \\
4.8 \\
3.5 \\
5.9 \\
2.1 \\
2.1 \\
1.6 \\
3.3 \pm 1.8\end{array}$ & $\begin{array}{l}2.3 \\
1.6 \\
5.6 \\
4.0 \\
3.0 \\
4.4 \\
3.9 \\
6.1 \\
1.8 \\
1.9 \\
1.9 \\
3.3 \pm 1.6\end{array}$ & $\begin{array}{c}3.3 \\
2.9 \\
6.2 \\
3.8 \\
5.5 \\
10.0 \\
9.2 \\
6.8 \\
3.8 \\
4.6 \\
3.2 \\
5.4 \pm 2.4\end{array}$ & $\begin{array}{c}3.9 \\
3.3 \\
6.8 \\
4.9 \\
5.7 \\
13.2 \\
8.7 \\
7.5 \\
4.1 \\
6.7 \\
3.7 \\
6.2 \pm 2.9\end{array}$ \\
\hline
\end{tabular}

p values with paired t test. Abbreviations: EF, ejection fraction; ESWS/ESVI, ratio between end-systolic wall stress and end-systolic volume index. 

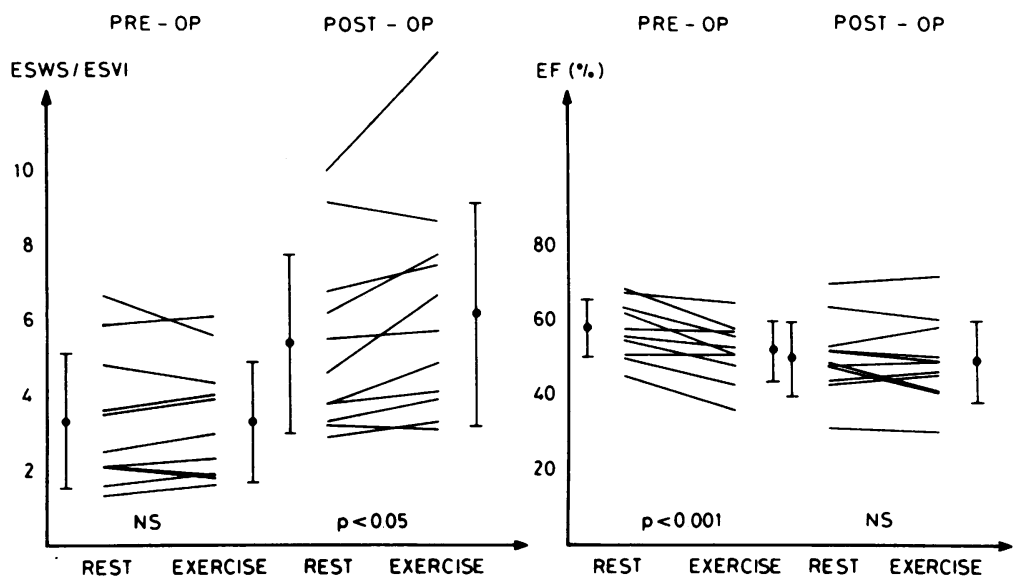

Fig. 2 Effect of mitral valve replacement on left ventricular response to isometric exercise. Preoperatively the end-systolic wall stress/volume ratio remained unchanged during exercise, but increased significantly postoperatively (left panel). The ejection fraction decreased preoperatively during exercise, but remained unchanged after mitral valve replacement (right panel).

remained unchanged during exercise both before and after operation. Table 5 presents the individual values for the ejection fraction and the end-systolic wall stress/volume ratio at rest and during exercise. The ejection fraction decreased during exercise before operation, but remained unchanged after operation (Fig. 2). The end systolic wall stress/volume ratio remained unchanged before operation, but increased significantly after operation during exercise (Fig. 2). The end-systolic wall stress increased from $195 \pm 46$ $\mathrm{g} / \mathrm{m}^{2}$ to $226 \pm 50 \mathrm{~g} / \mathrm{m}^{2}(\mathrm{p}<0.001)$ during the handgrip exercise before operation, and from $252 \pm 50 \mathrm{~g} / \mathrm{m}^{2}$ to $289 \mathrm{~g} / \mathrm{m}^{2}(\mathrm{p}<0.001)$ after operation.

\section{Discussion}

A regurgitant mitral valve is an unloading device that allows the contractile force of the left ventricle to be expended more in shortening the myocardial fibres than in the development of tension. Because of this systolic unloading, the measures of ventricular function, such as the ejection fraction, which depend on the ventricular afterload, may overestimate myocardial function. ${ }^{5}$ Thus the end-systolic stress volume relations, which are practically independent of the loading conditions, ${ }^{11} 12$ can be regarded as more reliable for evaluating ventricular function in patients with mitral regurgitation.

Reports concerning the effect of mitral valve replacement on ventricular function in mitral regurgitation have shown the ejection phase contractile indices to decrease after surgery. ${ }^{34}$ Since none of these studies has taken into consideration the altered load- ing conditions after operation, the true effect of valve $\mathscr{\omega}_{\omega}^{\infty}$ replacement on myocardial function remains to be determined. Our data indicate that the ventricularo function, as expressed by the end-systolic wall stress/근 volume ratio, improves after operation. This is in agreement with the postoperative improvement noted $\stackrel{\odot}{\mathbb{Q}}$ in the functional class and clinical state. Our policy has been not to recommend operation for patientsō with poor preoperative ventricular function, and thus $\exists$ none of our patients had irreversible ventricular dysfunction. Though the end-systolic wall stress/volumeratio increased, the ejection fraction decreased after $\vec{\sigma}$ operation, as also noted by others. ${ }^{34}$ The reason for this decrease was mainly a reduction in end-diastolico volume with no concomitant reduction in end-systolic 3 . volume, probably because of the increased afterloado caused by a competent mitral valve. In other volume overload states, as in aortic regurgitation, where theo afterload is not usually reduced preoperatively, the abolition of volume overloading results in a decreaseo in both the end-systolic and end-diastolic volume. ${ }^{11} \mathrm{~N}$

Isometric exercise has been used for evaluating left . ventricular contractile reserves in various cardiovascu- $N$ lar disorders. ${ }^{14-16}$ The handgrip exercise significantly increases the afterload on the heart ${ }^{14}$ and can there- 0 fore be regarded as a useful means of exerting stress on the left ventricle in mitral regurgitation, where the afterload stress caused by isometric exercise? unmasked the left ventricular dysfunction preopera- $\square$ tively. After mitral valve replacement the ventricular $\overrightarrow{0}$ response to exercise was improved, indicating an $\vec{\curvearrowright}$ associated improvement in the contractile reserves of the myocardium after operation. 
Reliable determination of the end-systolic wall stress/volume ratio requires highly invasive methods and is not suitable for serial measurement of left ventricular function preoperatively. Because of the poor postoperative results reported in patients with a low preoperative ratio, ${ }^{17}$ the non-invasive monitoring of ventricular function might be valuable in order to avoid irreversible myocardial dysfunction. The ejection fraction can easily be measured by non-invasive methods such as echocardiography 18 or nuclear angiography ${ }^{19}$ during isometric exercise. The noninvasive monitoring of the left ventricular response to isometric exercise might be helpful before operation in deciding upon the best time for operation, before irreversible myocardial dependence on reduced afterload has occurred.

\section{Conclusion}

Our data indicate that though the ejection fraction decreases, ventricular function, as assessed by the end-systolic wall stress/volume ratio, improves after mitral valve replacement in patients with mitral regurgitation. The ventricular response to afterload stress caused by isometric exercise also improves after operation. By unmasking ventricular dysfunction, isometric exercise testing may be helpful preoperatively in the non-invasive monitoring of the ventricular response to afterload stress. The non-invasive assessment of the possible development of reduced ventricular response to afterload stress in the course of time is needed, before preoperative isometric exercise testing can be regarded as helpful in making therapeutic decisions.

\section{References}

1 Pantely G, Morton M, Rahimtoola SH. Effects of successful, uncomplicated valve replacement on ventricular hypertrophy, volume, and performance in aortic stenosis and in aortic incompetence. $\mathcal{F}$ Thorac Cardiovasc Surg 1978; 75: 383-91.

2 Kennedy JW, Doces J, Stewart DK. Left ventricular function before and following aortic valve replacement. Circulation 1977; 56: 944-50.

3 Kennedy JW, Doces JG, Stewart DK. Left ventricular function before and following surgical treatment of mitral valve disease. Am Heart f 1979; 97: 592-8.

4 Schuler G, Peterson KL, Johnson A, et al. Temporal response of left ventricular performance to mitral valve surgery. Circulation 1979; 59: 1218-31.

5 Wong CYH, Spotnitz HM. Systolic and diastolic properties of the human left ventricle during valve replacement for chronic mitral regurgitation. Am $\mathcal{F}$ Cardiol 1981; 47: 40-9.

6 Dodge HT, Sandler H, Ballew DW, Lord JD Jr. The use of biplane angiocardiography for the measurement of left ventricular volume in man. Am Heart $\mathcal{F}$ 1960; 60: 762-70.

7 Lähde S. Cineangiographic determination of left ventricular volume: accuracy of methods. Acta Radiologica 1976; suppl 348.

8 Hammermeister KE, Murray JA, Blackmon JR. Revision of Gorlin constant for calculation of mitral valve area from left heart pressures. Br Heart $\mathcal{F}$ 1973; 35: 392-6.

9 Rackley CE, Dodge HT, Coble YD, Hay RE. A method for determining left ventricular mass in man. Circulation 1964; 29: 666-71.

10 Walker ML, Hawthorne EW, Sandler, H. Methods of assessing performance for the intact hypertrophied heart. In: Alpert NR, ed. Cardiac hypertrophy. New York: Academic Press, 1971: 387.

11 Sagawa K, Suga H, Shoukas AA, Bakalar KM. Endsystolic pressure/volume ratio: a new index of ventricular contractility. Am $\mathcal{Y}$ Cardiol 1977; 40: 748-53.

12 Grossman W, Braunwald E, Mann T, McLaurin LP, Green LH. Contractile state of the left ventricle in man as evaluated from end-systolic pressure-volume relations. Circulation 1977; 56: 845-52.

13 Clark DG, McAnulty JH, Rahimtoola SH. Valve replacement in aortic insufficiency with left ventricular dysfunction. Circulation 1980; 61: 411-21.

14 Amende I, Krayenbuehl HP, Rutishauser W, Wirz P. Left ventricular dynamics during handgrip. $\mathrm{Br}$ Heart $\mathcal{F}$ 1972; 34: 688-95.

15 Grossman W, McLaurin LP, Salz SB, Paraskos JA, Dalen JE, Dexter L. Changes in the inotropic state of the left ventricle during isometric exercise. $B r$ Heart $\mathcal{F}$ 1973; 35: 697-704.

16 Kivowitz C, Parmley WW, Donoso R, Marcus H, Ganz W, Swan HJC. Effects of isometric exercise on cardiac performance: the grip test. Circulation 1971; 44: 994 1002.

17 Carabello BA, Nolan SP, McGuire LB. Assessment of preoperative left ventricular function in patients with mitral regurgitation: value of the end-systolic wall stress-end-systolic volume ratio. Circulation 1981; 64: 1212-20.

18 Crawford MH, White DH, Amon KW. Echocardiographic evaluation of left ventricular size and performance during handgrip and supine and upright bicycle exercise. Circulation 1979; 59: 1188-96.

19 Bodenheimer MM, Baner VS, Fooshee CM, Gillespie JA, Helfant RH. Detection of coronary heart disease using radionuclide determined regional ejection fraction at rest and during handgrip exercise: correlation with coronary angiography. Circulation 1978; 58: 640-8.

Requests for reprints to Dr Heikki V Huikuri, Department of Medicine, University of Oulu, University Central Hospital, SF-90220 Oulu 22, Finland. 